\title{
On entering a new decade: Foolish old surgeons removing the mountains
}

\author{
Kun Hwang \\ Department of Plastic Surgery, Inha University School of Medicine, Incheon, Korea
}

The Korean Cleft Palate-Craniofacial Association (KCPCA), with its 28-year history, has developed into a well-regarded professional society with 1,228 members. In 2021, we are starting a new decade and we hope to make a new leap forward.

I am grateful to the members of the KCPCA for electing me as the 16th president of our association. It will be my last opportunity to serve the KCPCA since I have only 2 years before my retirement.

In my role as president, I would like to enhance knowledgesharing among our members by providing more opportunities for academic communication. I also hope to raise our association's status to a higher level in the global academic community. To achieve this goal, we will need active participation from all of our members.

Of particular note, our official journal, Archives of Craniofacial Surgery (ACFS), which was registered in PubMed Central (PMC) since 2014, was indexed in Scopus in 2019. As the president of the KCPCA and the ethics editor of ACFS, I will help the chief editor of ACFS for indexing ACFS in more databases. To echo the words of President John F. Kennedy, please do not ask what KCPCA can do for you, but ask what we can do for our KCPCA together. I eagerly hope that our members will submit valuable manuscripts to ACFS.

I know that being registered in MEDLINE or SCIE (Science Citation Index Expanded) may seem like a distant goal. However, it is not so far off that it cannot be reached eventually. A

Correspondence: Kun Hwang

Department of Plastic Surgery, Inha University School of Medicine, 27 Inhang-ro, Jung-gu, Incheon 22332, Korea

E-mail: jokerhg@inha.ac.kr

This study was supported by a grant from National Research Foundation of Korea (NRF-2020R1I1A2054761).

Received December 11, 2020 / Revised December 11, 2020 / Accepted December 14, 2020 well-known fable that emphasizes the virtues of perseverance and willpower comes to mind.

A 90-year-old foolish man (愚公) lived near a pair of mountains. He was annoyed by the obstruction caused by the two mountains and sought to dig through them with hoes and baskets. When questioned by his clever neighbor as to the seemingly impossible nature of his task, this foolish man replied that while he may not finish the task in his lifetime, through the hard work of himself, his children, and their children, and so on through many generations, someday the mountains would be removed if he persevered (Fig. 1). The gods in Heaven, impressed with his hard work and perseverance, ordered the mountains to be separated ("Foolish old man removes the mountains,”思公移山).

Perhaps the goals of achieving a higher level in the global academic community or attaining a glorious future will not be reached while I am the president of the KCPCA, or even before my retirement. However, I do believe that if we foolish old surgeons start building a stone bridge, one by one, to cross the stream, and if our junior surgeons continue the task, it will be completed someday in the future.

Indeed, “foolish old surgeons remove the mountains (醫公移山).”

\section{NOTES}

\section{Conflict of interest}

No potential conflict of interest relevant to this article was reported.

\section{ORCID}

Kun Hwang 


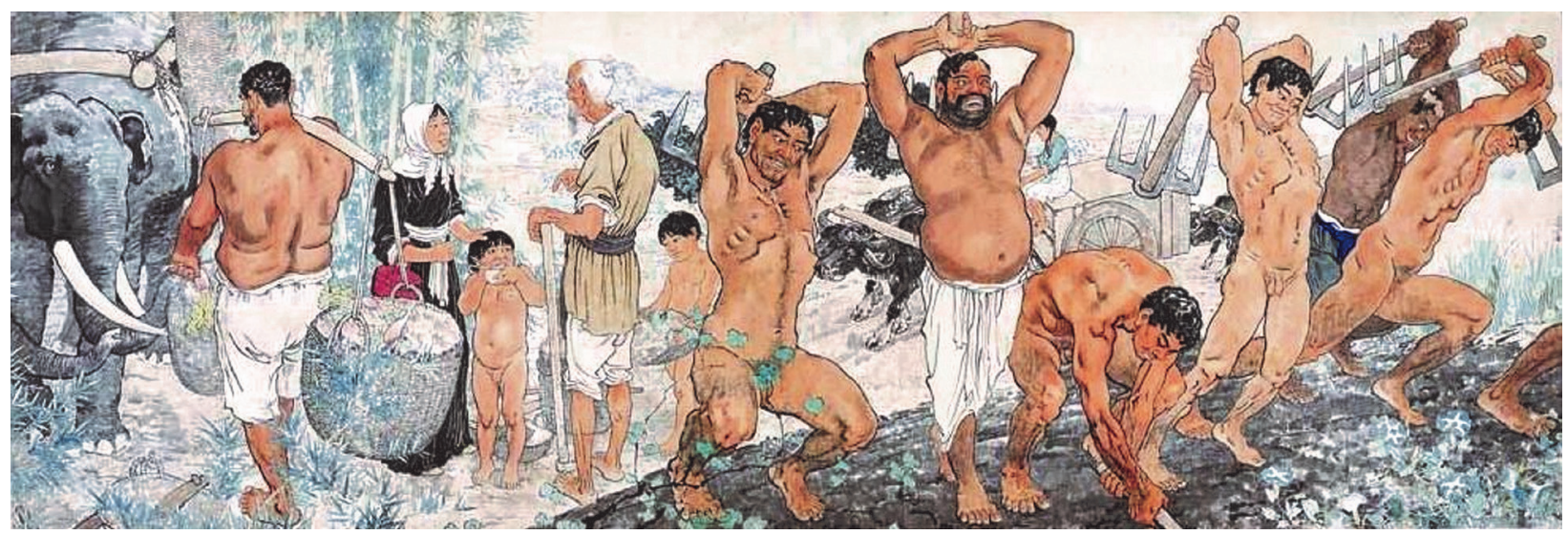

Fig. 1. A foolish old man removes the mountains (愚公移山) drawn by Xu Beihong (徐悲鸿) (1895-1953). Source: Wikimedia Commons. 